\title{
A relação entre a síntese e a degradação de proteínas na memória de reconhecimento de objetos
}

\author{
Bruna Freitas Saenger ${ }^{1}$; Iván Izquierdo²
}

\section{Resumo}

A consolidação é o processo através do qual uma nova informação é armazenada em uma memória de longa duração e, quando evocada, essa memória previamente consolidada requer uma nova fase de estabilização denominada de reconsolidação, sendo que ambos os processos necessitam da síntese de proteínas para que ocorram. Entretanto, recentemente se demonstrou que a consolidação e a reconsolidação de memórias são dependentes não só da síntese, mas também da degradação de proteínas através do sistema ubiquitina-proteassoma (UPS), o qual é considerado um dos principais mecanismos celulares responsável pelo turnover de proteínas. Assim, estudos demonstraram que o UPS participa no processo de consolidação e reconsolidação das memórias de medo e espacial, porém sua participação na memória de reconhecimento ainda não foi elucidada. O objetivo deste estudo é investigar a participação do UPS na consolidação e reconsolidação da memória de reconhecimento de objetos (RO), na região CA1 do hipocampo dorsal. Para isto, ratos Wistar Machos (3 meses de idade, 330g), com cânulas-guia implantadas na região CA1 do hipocampo dorsal através de cirurgia estereotáxica, foram treinados na tarefa de RO, na presença de dois diferentes objetos (A e B). 24 horas depois, os animais foram submetidos a uma sessão de reativação na presença de um objeto familiar e um novo (A e C). 24 horas depois, os animais foram submetidos a sessão de teste com diferentes combinações de objetos (A e $\mathrm{D}, \mathrm{B}$ e $\mathrm{D}$ ou $\mathrm{C}$ e D). As sessões de treino, reativação e teste tiveram 5 minutos de duração e se avaliou o tempo que o animal explorou cada um dos objetos (tocar, cheirar). As micro-infusões na região CA1 ocorreram imediatamente após a sessão de reativação. $\mathrm{O}$ inibidor do sistema ubiquitina-proteassoma, $\beta$-lactacistina (200 nmol/lado) não afetou a consolidação e a reconsolidação da memória de RO, enquanto o inibidor da síntese de proteínas, Anisomicina (375 nmol/lado) prejudicou a consolidação e a reconsolidação da memória de RO. No entanto, o bloqueio do UPS foi capaz de reverter o prejuízo causado pela inibição da síntese de proteínas na

\footnotetext{
${ }^{1}$ Graduanda em Medicina pela Universidade Luterana do Brasil, bolsista científica no Centro de Memória na Pontifícia Universidade Católica do Rio Grande do Sul. brunasaenger@hotmail.com

2 Médico (1961) e Doutor em Medicina (1962) pela Universidade de Buenos Aires. Professor Titular de Medicina, coordenador do Centro de Memória e coordenador de Altos Estudos do Instituto do Cérebro da Pontifícia Universidade Católica do Rio Grande do Sul.
} 
reconsolidação na região CA1 do hipocampo. Portanto, o UPS não é necessário por si só, para que ocorra a consolidação e a reconsolidação da memória de RO, porém é capaz de reverter o prejuízo causado pela inibição da síntese proteica, demonstrando uma relação direta entre a degradação e a síntese de proteínas durante a reconsolidação da memória de RO.

Palavras Chave: Memória de reconhecimento; Hipocampo; Consolidação; Reconsolidação; Síntese de proteínas; Degradação de proteínas 